\title{
The Fourth Annual Meeting of the International Network for Pediatric Hemophilia: Current Challenges and Recommendations in the Clinical Care of Children with Hemophilia
}

\author{
Rolf Ljung $^{a} \quad$ Marijke van den Berg $^{b} \quad$ Leonard A. Valentino ${ }^{c} \quad$ Michael Manco-Johnson $^{d}$ \\ ${ }^{a}$ Department of Pediatrics and Malmö Center for Thrombosis and Hemostasis, Skåne University Hospital, Lund University, Malmö, Sweden \\ ${ }^{\mathrm{b}}$ Meander Hospital, Board of Directors, Amersfoort, the Netherlands \\ ${ }^{c}$ Department of Pediatrics and Internal Medicine, Rush Hemophilia \& Thrombophilia Center, Rush University Medical Center, Chicago, IL, \\ ${ }^{\mathrm{d}}$ Department of Radiology and University of Colorado Denver Hemophilia \& Thrombosis Center, \\ University of Colorado Health Sciences Center, Aurora, CO, USA
}

\section{Keywords}

Hemophilia · Pediatric · Inhibitor development .

Hemophilia arthropathy

\section{Summary}

The International Network for Pediatric Hemophilia (INPH) comprises a group of physicians committed to the unique care of and challenges facing pediatric hemophilia patients. By collaborating on an international level, extensive experience can be shared on current practice, new trends can be discussed and scientifically valid studies can be developed and performed. The three overall objectives of the group (scientific progress, education and networking) are achieved at each annual meeting starting with a round table on the members' current research and clinical activities, project reports of INPH study initiatives, followed by invited educational presentations and interactive discussions. The meetings close with proposals of new projects, future directions of the group and concluding remarks. The Fourth Annual INPH meeting, held in 2009 in Boston, MA, USA, focused on inhibitor development and hemophilic arthropathy in the clinical care of children with hemophilia.

\section{Schlüsselwörter}

Hämophilie · Pädiatrisch · Inhibitorentwicklung · Hämophilie-Arthropathie

\section{Zusammenfassung}

Das International Network for Pediatric Hemophilia (INPH) wird von einer Gruppe von Ärzten gebildet, die sich der speziellen Behandlung von Kindern mit Hämophilie und den damit verbundenen Herausforderungen verpflichtet fühlen. Durch die Kollaboration auf internationaler Ebene, können vielfältige Erfahrungen in der klinischen Praxis geteilt, neue Entwicklungen diskutiert und wissenschaftlich valide Studien geplant und durchgeführt werden. Die drei übergeordneten Zielvorgaben der Gruppe (Wissenschaft, Fortbildung und Zusammenarbeit) sind bei jedem der jährlichen Treffen des INPH sichtbar, die mit einem Rundtischgespräch über die aktuelle Forschung und klinische Aktivitäten der Mitglieder beginnen und dann ihre Fortsetzung finden in Projektberichten der INHP-Studieninitiativen, eingeladenen Fortbildungspräsentationen und interaktiven Diskussionen. Die Treffen enden mit Vorschlägen für neue Projekte, Überlegungen zur zukünftigen Ausrichtung der Gruppe sowie abschließenden Bemerkungen. Die 4. jährliche INPH-Tagung, die 2009 in Boston, MA, USA, stattfand, beschäftigte sich schwerpunktmäßig mit der Inhibitorentwicklung und der Hämophilie-Arthropathie in der klinischen Versorgung von Kindern mit Hämophilie.

\section{KARGER}

Fax +497614520714

Information@Karger.de

www.karger.com
(C) 2010 S. Karger GmbH, Freiburg 


\section{Update on INPH Project Initiatives}

As a component of the scientific objective of the group, INPH members jointly plan and conduct studies in pediatric hemophilia. Updates on the currently approved studies were provided at the annual meeting. One such study was the International Female Hemophilia Study led by Donna DiMichele, Weill Cornell Medical College, New York, NY, USA, which addresses the lack of current clinical data on genetic etiology, mutation analysis and quality of life in females with severe or moderately severe hemophilia A and B. A total of 34 female subjects from hemophilia treatment centers throughout the world have been identified via INPH, European Paediatric Network for Haemophilia Management (PedNet) and word of mouth. At the time of publication of this meeting report, the protocol was amended to reflect a case control design as recommended by the INPH investigators and has received institutional ethical approval and has been redistributed to participating centers for local ethical approval. Subject accrual is anticipated to be completed by the end of 2010. Another project initiative discussed at the meeting was the adherence scale study by Natalie Duncan and Amy Shapiro, both from Indiana Hemophilia and Thrombosis Center, Indianapolis, IN, USA. This involved the new hemophilia regimen adherence scales VERITAS-Pro [1] and VERITAS-PRN [2]. These scales have been developed in US English, and translations will be produced and validated for international use. The last of the project updates presented at the INPH meeting was on intracranial hemorrhage ( $\mathrm{ICH}$ ) and led by Rolf Ljung, Lund University, Malmö, Sweden. This project aims to improve the quality of care of children with hemophilia by investigating the mortality and morbidity caused by $\mathrm{ICH}$ and whether or not it can be improved by the studied treatment regimen. The data from this initiative will be ready for evaluation in 2013. The ICH study will be performed within the existing infrastructure of INPH (as well as PedNet) with high institutional and personal competence for scientific work.

\section{Invited Presentations and Interactive Discussions}

\section{Inhibitor Development and Clinical Management}

Marijke van den Berg, University Hospital Utrecht, Utrecht, the Netherlands, reported on the risk of inhibitor development and its effect on clinical practice. A clinical prediction score was created based on patient family history, high-risk FVIII gene mutations and intensive initial FVIII replacement treatment. To assess the validity of the included risk factors of the model, the investigators developed a questionnaire asking pediatric physicians in major hemophilia centers in Europe, Japan, USA and Canada to score specific factors for their possibilities of increasing inhibitor development. Responses from 46 physicians at 42 centers responsible for the care of 2,642 children with severe hemophilia A revealed that major gene defects and early intensive treatment were considered as risk factors for inhibitor development. Factors considered likely to reduce inhibitor development were early start of prophylaxis and avoidance of early elective surgery. The latter factors were scored by physicians as influential in changing management practices in children with severe hemophilia while they are at the highest risk of inhibitor development.

An interactive discussion of a few clinical scenarios following the presentation surveyed the members on their recommendations and practices. Fourteen members were in attendance at the meeting. The clinical scenarios pertained to the first 15-20 patient exposure days of FVIII. When asked whether physicians do not recommend giving prophylactic injections if the pediatric patient has a temperature or any kind of infection, only two members agreed that they would not treat if the child had a temperature. All members agreed that they would avoid a surgical procedure such as insertion of a Port-A-Cath system during the first 15-20 exposure days. Ten members preferred to start with approximately $25 \mathrm{IU} / \mathrm{kg}$ instead of $50 \mathrm{IU} / \mathrm{kg}$ to avoid excessive exposure to FVIII, emphasizing that physicians are concerned about dose. In response to a scenario of whether it is important to administer FVIII on a regular basis after treatment of the first bleed (i.e. at least once/week), whether it is needed or not, the consensus was that the type of exposure matters and that they would regularly administer FVIII only in certain instances, such as a hip bleed. When asked if in their own clinical practice the physicians have the same treatment policy for hemophilia B as in hemophilia A, there were mixed responses and no conclusive opinions. The members were asked whether they would prefer to initially treat a boy with a high genetic risk to develop an inhibitor with pdFVIII, however a consensus was never reached. The majority of members did indicate that in their clinical practice, they try to predict genetic risk of inhibitor development by characterizing the mutation in the FVIII gene.

\section{Joint Arthropathy in Hemophilic Children}

Leonard Valentino, Rush University Medical Center, Chicago, IL, USA, reported on the pathophysiology of hemophilic arthropathy in animal model studies, and Michael Manco-Johnson, University of Colorado Health Sciences Center, Aurora, CO, USA, discussed the imaging modalities available to detect the pathophysiological process in a joint [3]. Joint injury in hemophilic mice revealed swelling of the joint, bleeding into soft tissue, increased cellular proliferation in the synovial membrane and intense inflammation after inducing joint injury [4]. Age affects the development of arthropathy in hemophilic mice and although both skeletally mature and immature joints are susceptible to the effects of hemarthrosis, the response may be different. Concerted angiogenic, proliferative and inflammatory pathways are key mechanisms causing blood-induced joint disease $[5,6]$. Consequently, successful maintenance of joint health may require multiple approaches during the pediatric period. 
A key challenge in providing early treatment against joint disease is the detection or imaging of joint damage itself. As presented by Michael Manco-Johnson, ultrasound, a relatively new technique being used in hemophilia, can visualize peripheral cartilage, synovium, blood and fluid, but not central cartilage or bone. X-ray is well-tested for assessing hemophilic arthropathy, reliable and the only modality to assess hemophilic joint replacement. MRI is now accepted as the best imaging technique for hemophilic arthropathy due to the ability to visualize the cartilage in the entire joint, synovium, hemosiderin, bone marrow edema, bone cysts and joint effusion. Powerful tools now exist to help evaluate the effectiveness of therapeutic intervention in hemophilic arthropathy of all ages.

An interactive discussion of a few clinical scenarios specific to management of joint arthropathy followed the two presentations. In relation to the topic of pathophysiology of hemophilic arthropathy, the members were questioned on their recommendations for administration of drugs and treatment of injury sites. As a result of the discussion, the consensus of the group was that blood ideally, however usually not feasible, should be removed after a joint bleed from the site of injury. The use of non-steroidal anti-inflammatory drugs (e.g. Cox-2 inhibitors) was not considered by the vast majority of the participants to be of value during a period after a joint bleed. It was noted that there was no decrease in synovitis in mice receiving Celebrex prophylactically, suggesting that a Cox-2 inhibitor may not be useful for helping to treat hemophilic arthropathy. In contrast there was some agreement that intraarticular injections of steriods as well as a short period with oral steriods (i.e. 1-2 weeks) may be of value to decrease the synovitis after a joint bleed. On the subject of imaging the pathophysiological process in hemophilic arthropathy, the members were first asked whether plain X-ray should be used routinely at a certain age during childhood to monitor joint outcome. There was generally great concern expressed regarding the exposure of small children to repeated X-rays; so the practice of routine X-rays was not recommended. On the other hand, in response to whether MRI should be used at a certain age during childhood to monitor joint outcome, some agreed that MRI should be done in early adolescence.

\section{Conclusion}

The meeting concluded with remarks from the chairperson Rolf Ljung on the future directions of the group and summarization of the main points from the presentations. The group reiterated their commitment to the specific challenges associ- ated with pediatric hemophilia. Members expressed appreciation of the forum as a mechanism to work together, solicit ideas and gather feedback for studies in planning or in progress as well as international clinical practice recommendations. The INPH group furthers scientific research through project collaborations and the ability to recruit patients on an international level for both individual studies and group proposals. The annual meeting educates the group on cutting edge practices and current data through invited presentations. A large benefit of the meeting is the networking opportunity between physicians from all over the globe for exchange of ideas and collaboration. The INPH intends to expand its reach through publication, networking and word of mouth. Although INPH is sponsored by Bayer HealthCare (Montville, NJ, USA), the direction of the group is academic and conducted independent of industry influence. This model has proven extremely effective and productive and can be adopted in a variety of rare therapeutic areas.

\section{Acknowledgements}

The authors thank Jocelyn Hybiske, $\mathrm{PhD}$, an independent medical writer for writing and editorial assistance. INPH is supported by funding from Bayer HealthCare.

\section{Appendix}

The members of INPH do not represent their respective countries or any national organization.

Scientific Chairperson: Rolf Ljung, Malmö, Sweden.

Members in Attendance: Thomas Abshire, Milwaukee, WI, USA; Manuel Carcao, Toronto, ON, Canada; Donna DiMichele, New York, NY, USA; Marilyn Manco-Johnson, Denver, CO, USA; Raina Liesner, London, UK; Catherine Manno, New York, NY, USA; Johannes Oldenburg, Bonn, Germany; Elena Santagostino, Milan, Italy; Amy Shapiro, Indianapolis, IN, USA; Ming-Chen Shen, Taipei, Taiwan; Midori Shima, Nara, Japan; Masashi Taki, Yokohama, Japan; Marijke van den Berg, Utrecht, the Netherlands.

Members Not Available for Meeting: Chris Barnes, Melbourne, Australia; Hervé Chambost, Marseilles, France; Georges-Etienne Rivard, Montreal, QC, Canada.

Guest Speakers: Natalie Duncan, Indianapolis, IN, USA; Michael Manco-Johnson, Denver, CO, USA; Leonard A. Valentino, Chicago, IL, USA.

Observers: Tricia Gooljarsingh, Bayer HealthCare, Montville, NJ, USA; Roswita Neumann, Bayer HealthCare, Montville, NJ, USA

\section{Disclosure}

The authors declared no conflict of interest. 


\section{References}

1 Duncan N, Kronenberger W, Roberson C, Shapiro A: VERITAS-pro: a new measure of adherence to prophylactic regimens in haemophilia. Haemophilia 2010;16:247-255.

2 Duncan NA, Kronenberger WG, Roberson CP, Shapiro AD: VERITAS-PRN: a new measure of adherence to episodic treatment regimens in haemophilia. Haemophilia 2009;16:47-53.
Beeton K, De Kleijn P, Hilliard P, Funk S, Zourikian N, Bergstrom BM, Engelbert RH, Van Der Net JJ, Manco-Johnson MJ, Petrini P, Van den Berg M, Abad A, Feldman BM, Doria AS, Lundin B, Poonnoose PM, John JA, Kavitha ML, Padankatti SM, Devadarasini M, Pazani D, Srivastava A, Van Genderen FR, Vachalathiti R: Recent developments in clinimetric instruments. Haemophilia 2006;12(suppl 3):102-107.

4 Valentino LA, Hakobyan N, Kazarian T, Sorensen BB, Tranholm M: Prevention of haemarthrosis in a murine model of acute joint bleeding. Haemophilia 2009;15:314-319.
5 Lafeber FP, Miossec P, Valentino LA: Physiopathology of haemophilic arthropathy. Haemophilia 2008;14(suppl 4):3-9.

6 Valentino LA, Hakobyan N, Enockson C: Bloodinduced joint disease: the confluence of dysregulated oncogenes, inflammatory signals, and angiogenic cues. Semin Hematol 2008;45(suppl 1): S50-57. 